\title{
Effect of Seasonal Variations on Some Physio-Chemical Properties of Tigris River water in Mosul City
}

\author{
Eman Sami Yaseen Al-Sarraj \\ Department of Biology, College of Science, University of Mosul, Mosul, Iraq \\ E-mail: emansami1160@gmail.com
}

(Received November 15, 2019; Accepted January 13, 2020; Available online September 01, 2020)

DOI: 10.33899/edusj.2020.126256.1027, ( ) 2020, College of Education for Pure Science, University of Mosul.

This is an open access article under the CC BY 4.0 license (http://creativecommons.org/licenses/by/4.0/).

\begin{abstract}
:
Water samples were collected from three sites along the Tigris River within the city of Mosul for the purpose of studying the seasonal variations of 2018 and 2019 on some environmental factors. It was studied by means of a set of field and laboratory tests that included Water temperature, Turbidity, Electrical conductivity, Total hardness (TH), Dissolved oxygen (DO), Biochemical oxygen demand $\left(\mathrm{BOD}_{5}\right)$, furthermore, measuring the concentration ions of chlorine, orthophosphates, nitrates, and sulfate.

The results showed that there is a clear fluctuation in the values of the factors under study, the Water temperature ranged between 14.2-25.4 ${ }^{\circ} \mathrm{C}$, and Turbidity between 2.8-23.1 NTU, and EC between 266-335 $\mu \mathrm{c} / \mathrm{cm}$, and the $\mathrm{pH}$ from 7.6-8.5, The DO was between 6.6-9.6 $\mathrm{mg} / 1$, the $\mathrm{BOD}_{5}$ 1.4-2.9 $\mathrm{mg} / 1$, the $\mathrm{TH}$ was $130-338 \mathrm{mg} / 1$, the CL 19.8-29.9 mg / 1, the $\mathrm{SO}_{4} 120-177 \mathrm{mg} / 1$, and the $\mathrm{NO}_{3}$ 0. 09-1.66 mg / 1, $\mathrm{PO}_{4} 0.011-0.036 \mathrm{mg} / 1$.

The study showed that all the values obtained were within the natural limits of local and international standards, although most of these values rise towards south of the city. The effect of discharge of the wastes, which are dumped directly without treatment, causes a change in the physical and chemical properties of water, especially in the areas where the valleys contact with the river, however, this effect fades away later due to the many factors like dilution, spreading, speed of flow and the increasing in water level.
\end{abstract}

Keywords: Tigris River water, Physical properties, Chemical properties, Mosul.

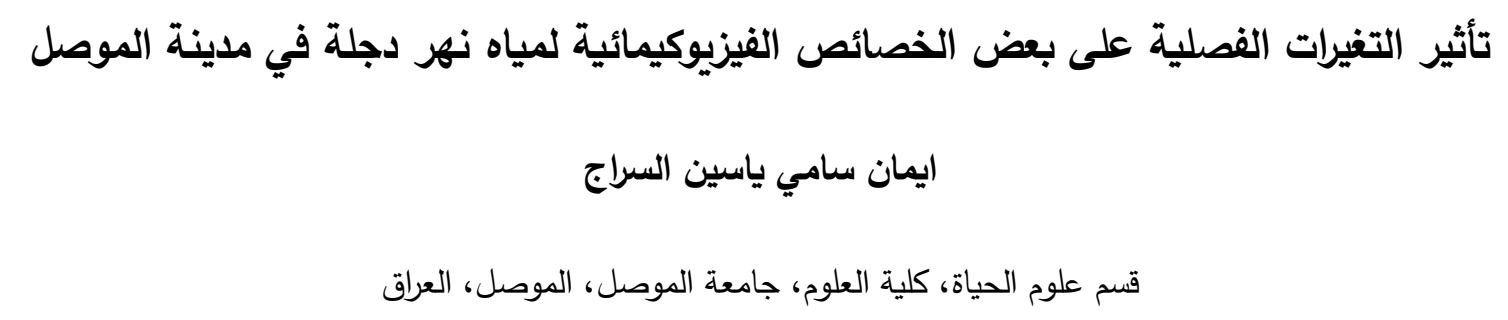

لغرض دراسة التغيرات الفصلية لعامي 2018 و2019 على بعض العوامل البيئية، جمعت عينات للمياه من ثلاثة مواقع

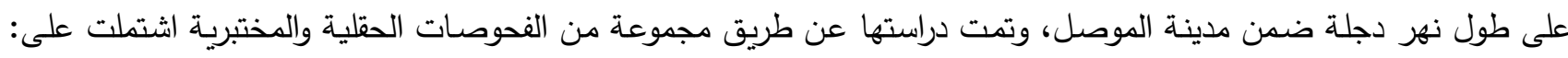

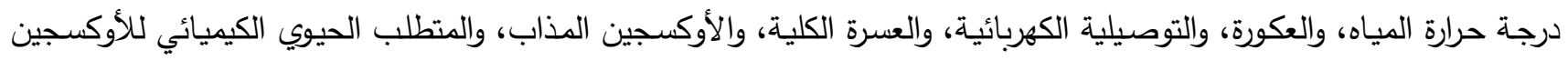


وكذلك قياس تركيز أيونات الكلوريد والاورثوفوسفات والنترات والكبريتات. أوضحت النتائج وجود تذبذب واضح في قيم العوامل قيد الدراسة، اذ تراوحت درجة حرارة المياه بين 14.2-25.4 م م، والعكورة بين 2.8-23.1 وحدة عكورة نيفلومترية، والتوصيل الكهربائي

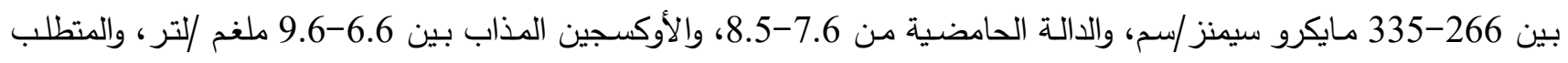

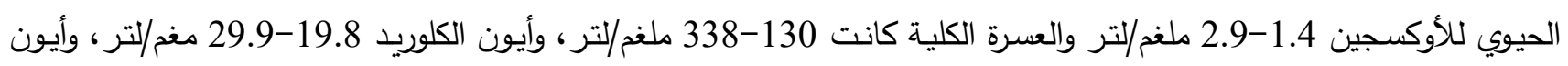

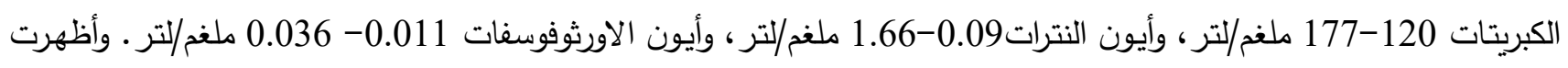

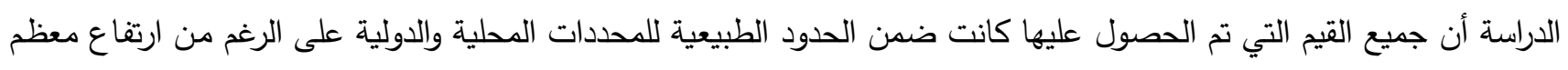

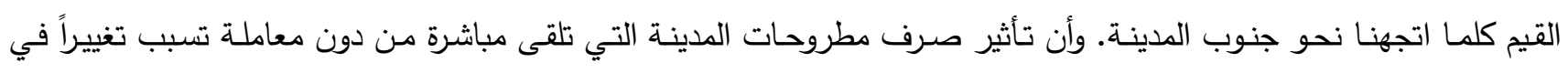

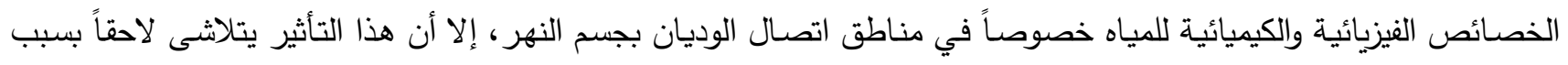
عامل التخفيف والانتشار وسرعة جريان المياه وزيادة منسوب الماء. الكلمات الدالة: مياه نهر دجلة، خصائص فيزيائية، خصائص كيميائية، الموصل.

\section{Introduction المقدمة}

لقد نال نهر دجلة في مدينة الموصل قسطاً كبيراً من اهتمام الباحثين في مجالات البيئة من أجل متابعة التغيرات التي تطرأ

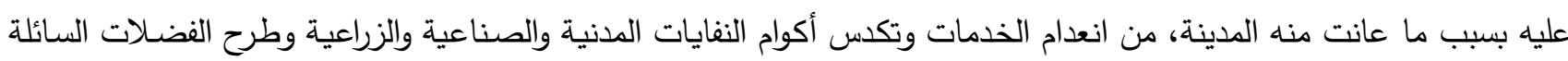

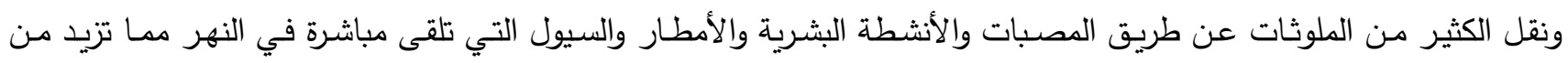

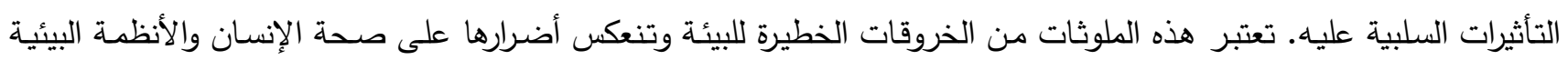
والتطور الحضاري، إضافة إلى خطورتها في التتوع الحياتي وبالتالي في السلسلة الغذائية [1].

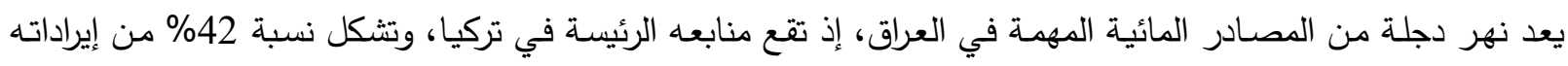

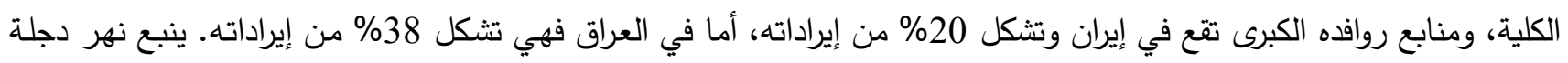

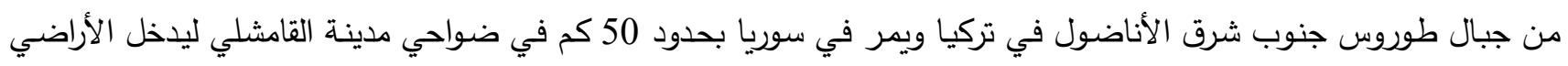

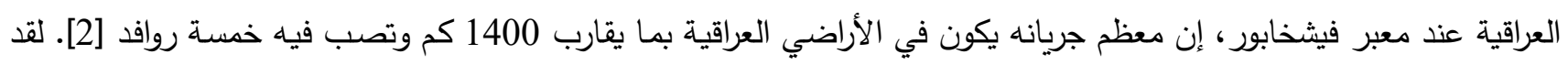

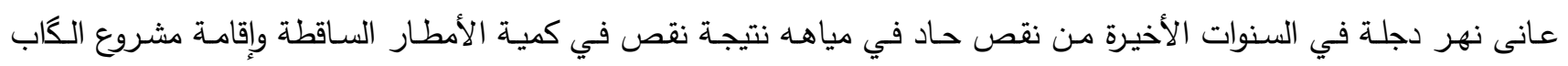

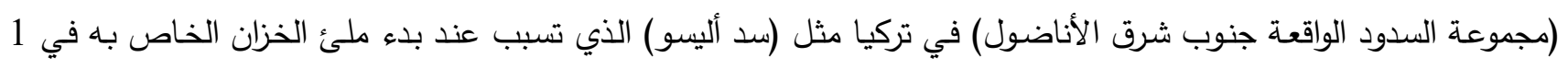

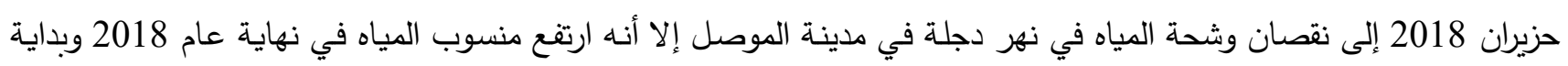

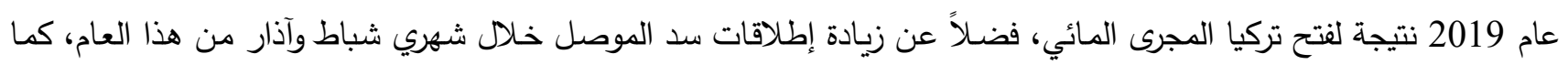

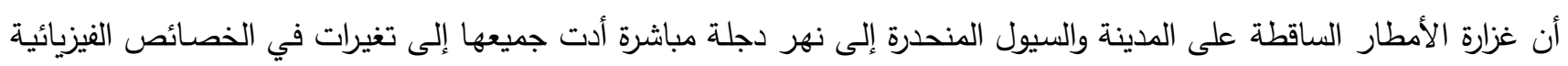
والكيميائية لمياهه ضمن مدينة الموصل. الهذف من الدراسة

من أجل زيادة المعلومات عن نوعية مياه نهر دجلة تم اختيار ثلاثة مواقع على طول النهر ضمن مدينة الموصل (الثكل 1) لتكون هدفاً للدراسة الحالية وهي كما يأتي: الموقع الأول: منطقة الرشيدية شمال الموصل.

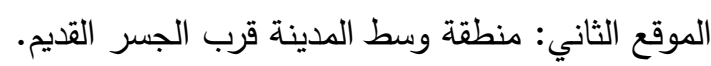
الموقع الثالث: منطقة ما بعد الجسر الرابع باتجاه جنوب المدينة. 


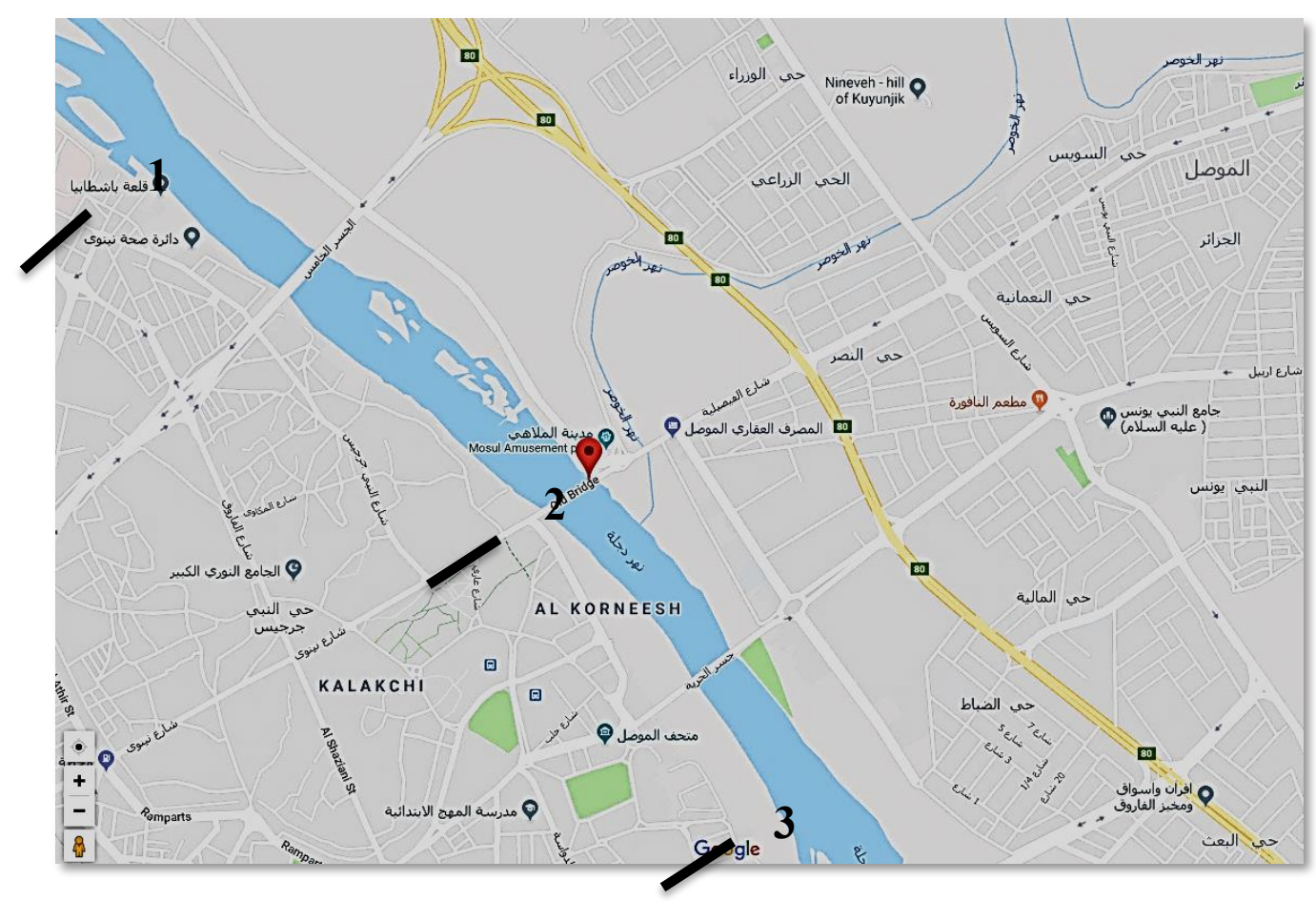

(الشكل) يبين مواقع الدراسة على نهر دجلة ضمن مدينة الموصل مأخوذة من (Google Earth)

جمعت العينات ابتداءً من شهر تموز 2018 ولغاية شهر آذار 2019 بواقع نموذج واحد شهرياً، لإجراء الفحوصات الفيزيائية

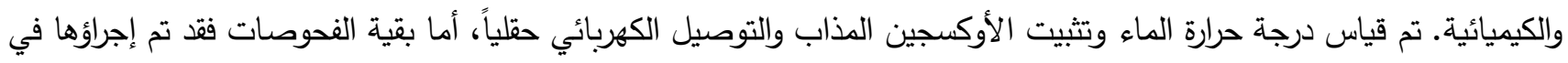
المختبر.

Materials and Methods المواد وطرائق العمل لغرض تحديد نوعية المياه، أجريت على العينات مجموعة من الفحوصات التي ذكرها APHA [3] وكما يأتي: العمل المختبري الفحوصات الفيزوكيميائية درجة الحرارة: تم قياس درجة حرارة المياه باستخدام محرار زئبقي بوحدة درجة مئوية ْم. التوصيل الكهربائي: تم قياس قابلية التوصيل الكهربائي باستخدام جهاز حقلي وبوحدة مايكروسيمينز/سم. العكورة: قيست العكورة باستخدام جهاز Turbidity Meter وعبّر عنها بوحدة Nephelometric Turbidity Unit (NTU). الادالـة الحامضسية (pH): قيست باستخدام pH meter بعد ضبط ومعايرة الجهاز باستعمال المحاليل المنظمـة ذات قيم دالـة حامضية 4,7,9 . Azid الأوكسـين المـاب DO2 بعد تثبيت الأوكسجين المذاب بالمحاليل القياسية حقلياً اعتمـاداً على طريقة وينكلر المحورة Modification المتطلب الحيوي الكيميائي للأوكسجين BOD5: تم تقدير تركيز BOD5 بالاعتماد على طريقة وينكلر لقياس الأوكسجين المذاب،

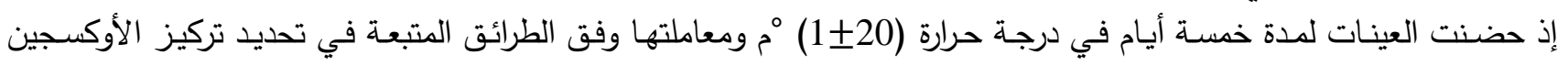
المذاب. 
العسرة الكليـة TH: استخدمت طريقـة التسحيح Titration method ضد اثيلين ثنائي الامين ربـاعي حامض الخليك ثنائي الصوديوم Na2EDTA.

$$
\text { تقدير ايونات الكلوريد Cl-1 }
$$

تقدير أيون الكبريتات SO4 كبريتات الباريوم، قيست كمية الضوء المشتت باستخدام جهاز المطياف الضوئي Spectrophotometer عند طول موجي 420 نانوميتر وعبر عن الناتج بوحدة ملغم/لتر .

تقدير أيـون النترات NO3

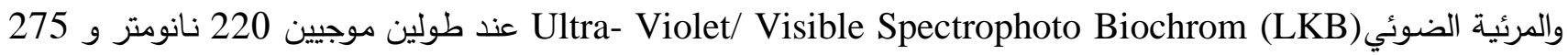
نانومتر وأخذ الفرق بين القراءتين, عبر عن الناتج بوحدة ملغم/لتر . تقدير أيسون الأرثوفوسفات PO4:-3: تم استخدام طريقة كلوريد القصديروز Stannous Chloride بتكوين معقد أزرق, قيست الامتصاصية بجهاز Spectrophoto meter عند طول موجي 690 نانومتر , عبر عن الناتج بوحدة ملغر/ لترون .

Results and Discussion النتائج والمناقشة خلال الدراسة الحالية لوحظ تذبذب لمنسوب مياه نهر دجلة , اذ تراجعت كمية المياه خلال صيف العام 2018م بسبب البداء

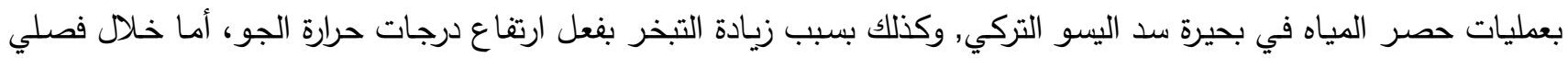

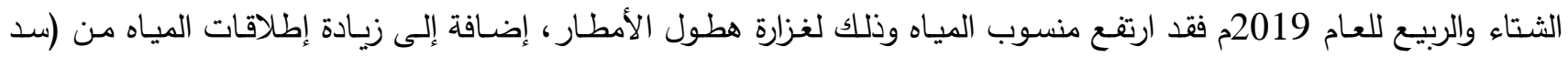

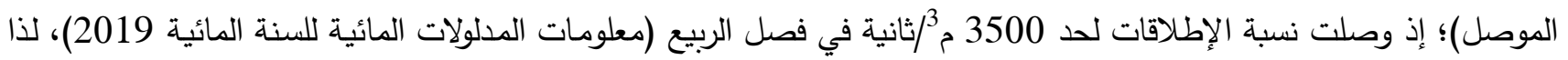
أظهرت النتائج تذبذب وتباين في قيم معظم الخصائص الفيزيائية والكيميائية للمواقع الثلاثة خلاد فصول النيات السنة (الجدول، 1)، وفيما يأتي عرض لنتائج الدراسة الحالية . درجـة حرارة المياه: تراوحت درجة حرارة المياه بين 14.2 و25.4 ْم في المواقع قيد الدراسة (الثكل2) نتيجةً لتأثر المياه بحرارة

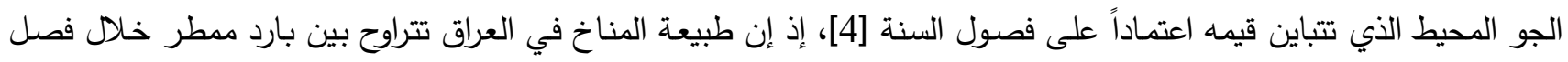
الثتاء إلى حار جاف خلال فصل الصيف [2] و [5] و [6].

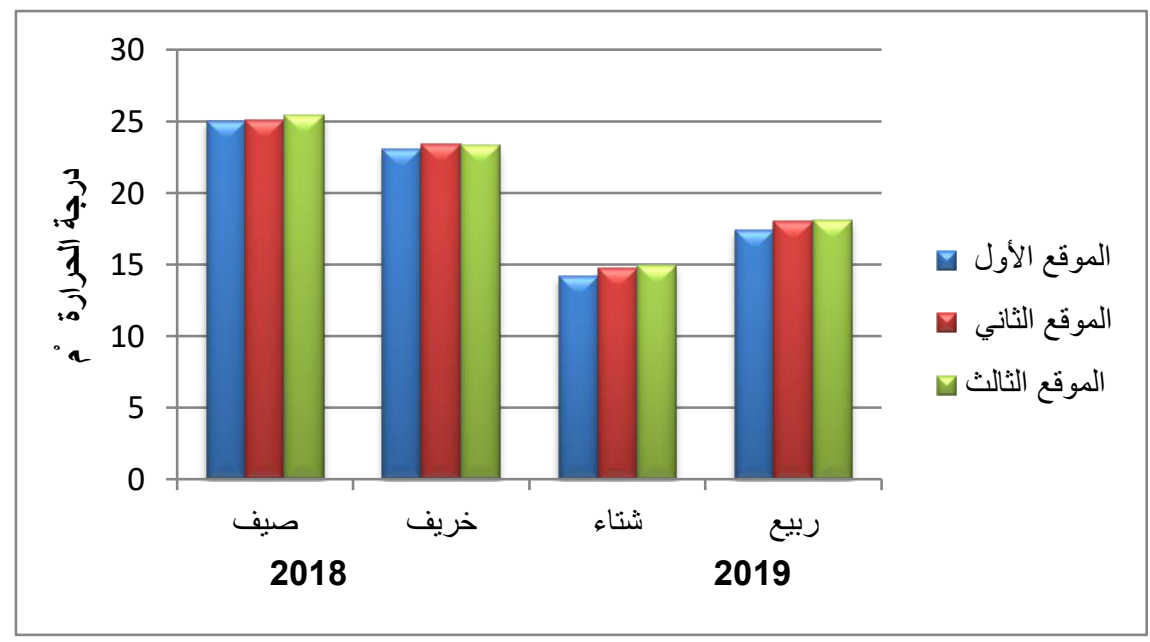

(الشكل2) قيم درجات حرارة المياه لمواقع الدراسة خلال فصول السنة 
العكورة: ازدادت قيم العكورة من 2.8 وحدة عكورة نفلومتريـة خلال فصل الصيف حتى بلغت 23.1 وحدة عكورة نفلومتريـة خلال

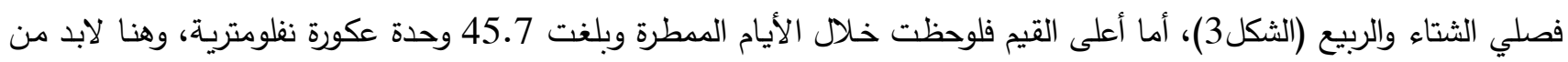

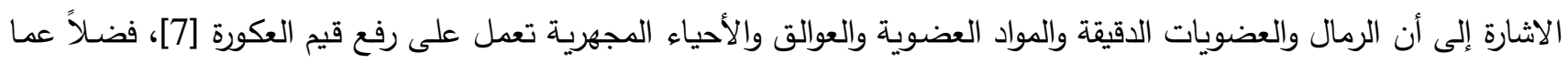

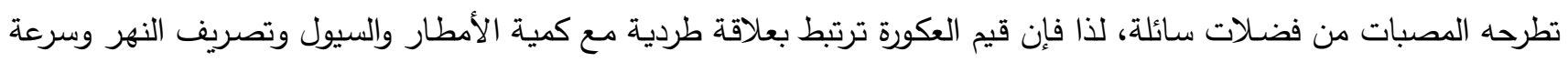
التيار [6] و [8].

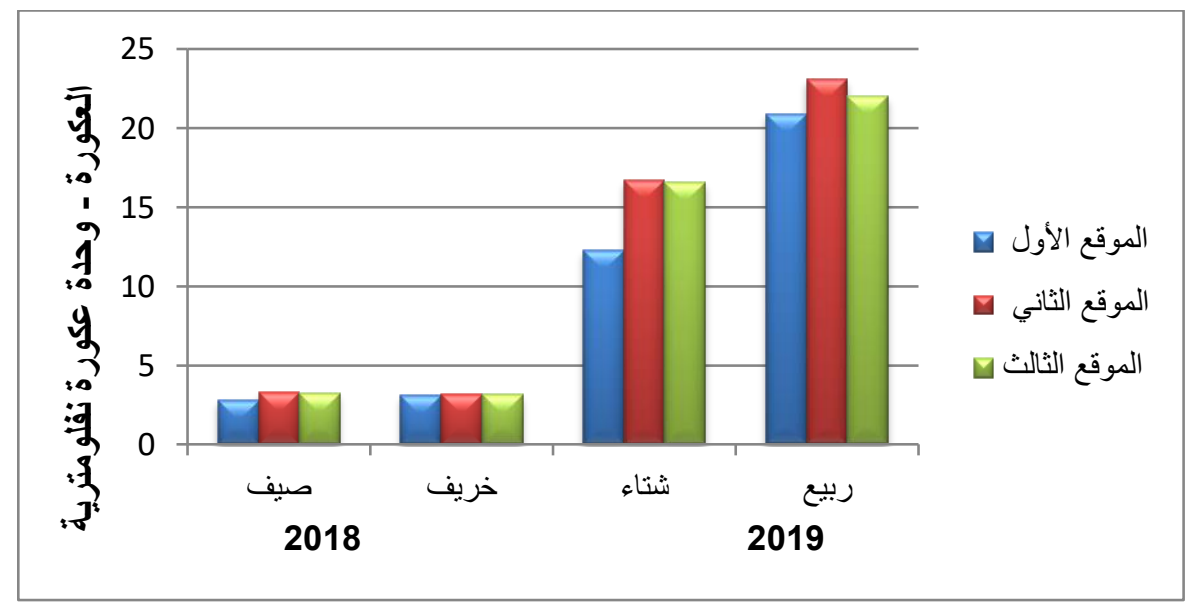

(الثكل3) قيم العكورة للمواقع المدروسة خلال فصول السنة

التوصيل الكهبائي: تشير النتائج في (الثكل4 ) الى أن قيم التوصيل الكهربائي لمياه نهر دجلة قد تراوحت خلال فترة الدراسة ما

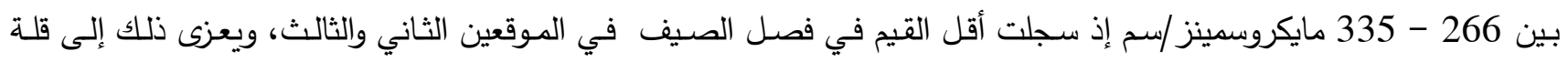
منسوب المياه أثناء فترة فصل الصيف، أما سبب ارتفاع القيم خلال فصل الربيع في المواقع المدروسة فيعود الى غزارة الأمطار وما

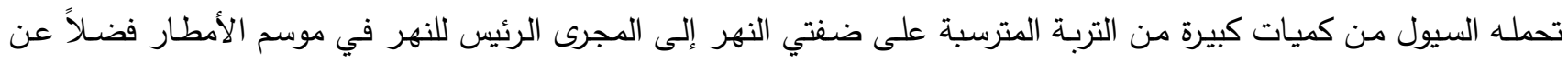

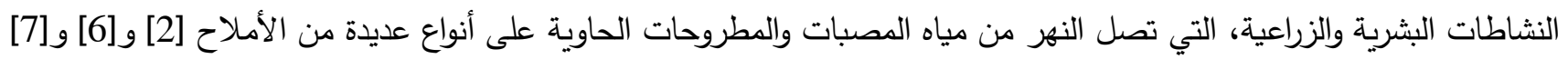

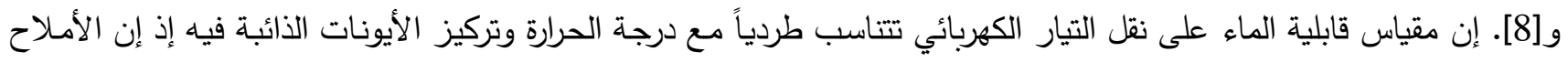
التي تصل النهر مع مياه السيول تجري ضمن الأراضي الزراعية مما تزيد من تركيزها في المياه الطبيعية [9].

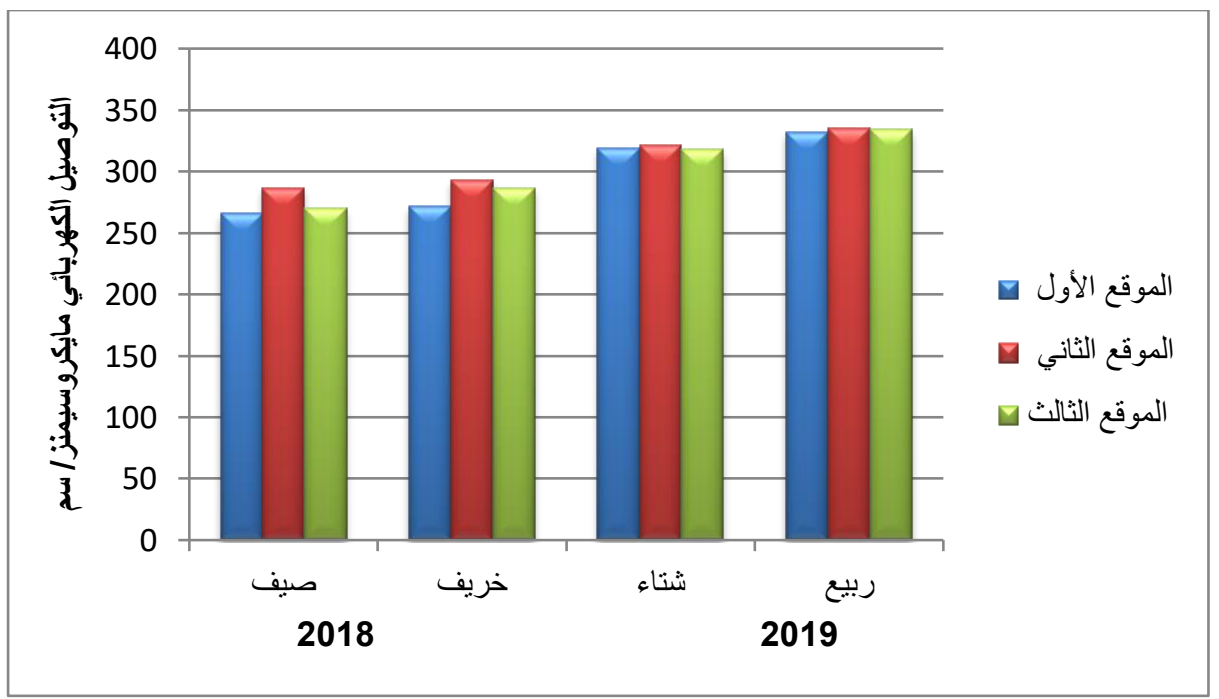

(الثكل4) قيم التوصيل الكهربائي للمواقع المدروسة خلال فصول السنة 
الدالـة الحامضية: إن قيمة الدالة الحامضية تميل نحو القاعدية قليلاً بسبب وجود أيونات الكاربونات والبيكاربونات في الصخور

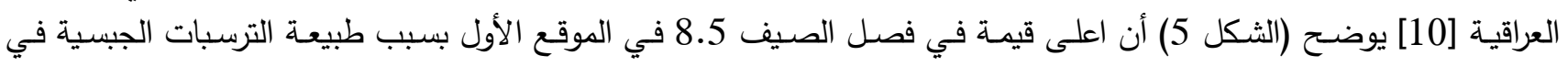

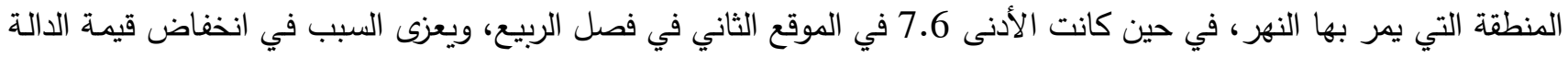

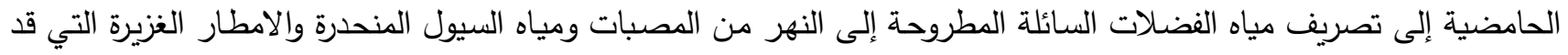

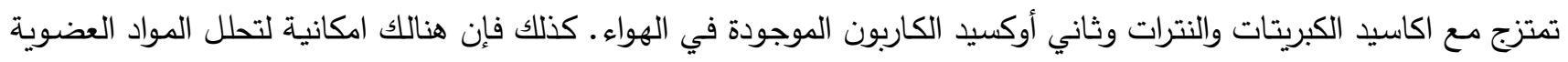

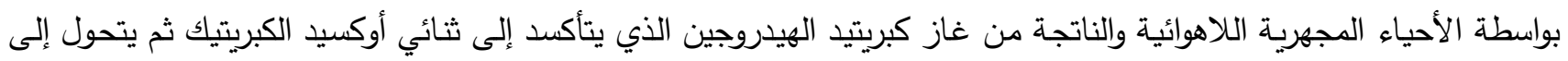
حامض الكبريتيك مما يؤدي إلى خفض الدالة الحامضية [8] و[11] كنداء

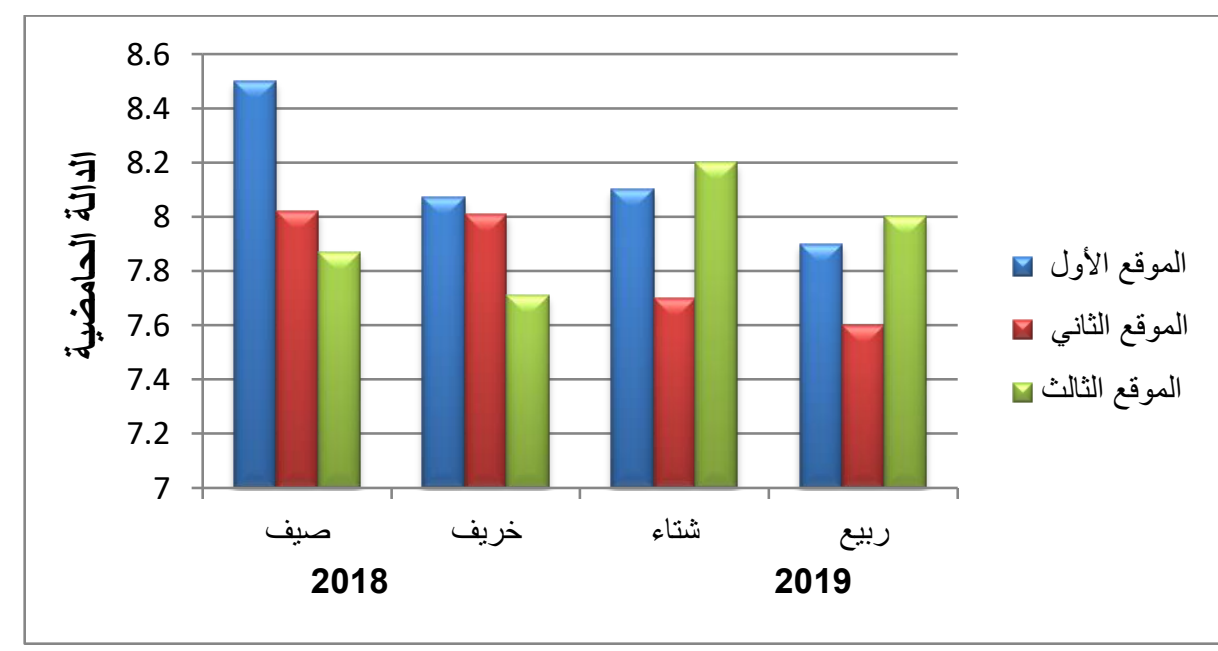

(الشكل5) قيم الدالة الحامضية للمواقع المدروسة خلال فصول السنة

الاوكسجين المذاب: أظهرت النتائج في(الثكل 6) أن أعلى تركيز للأوكسجين المذاب 9.60 ملغم / لتر قد تمت ملاحظته خلال

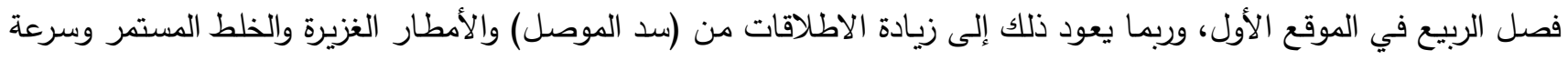

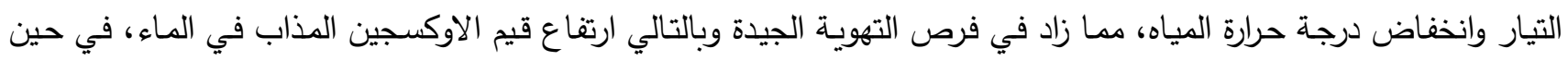
سجلت أقل تركيز للأوكسجين المذاب في فصل الصيف 6.6 ملغم / لتر في الموقع الثاني بسبب انخفاض مناسيب المياه وركودها

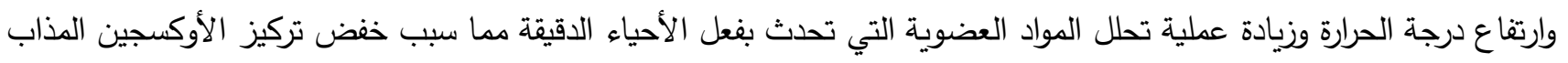

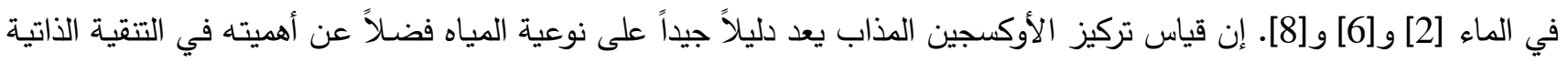

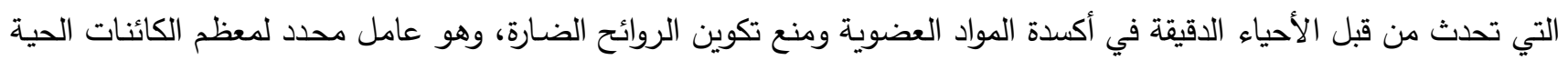
المائية باستثناء الأشكال اللاهوائية [12]. إن ارتفاع عمود الماء وزيـادة سرعة الجريان يؤدي إلى التهويـة الجيدة وكذلك الأمطار

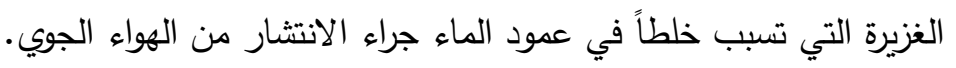




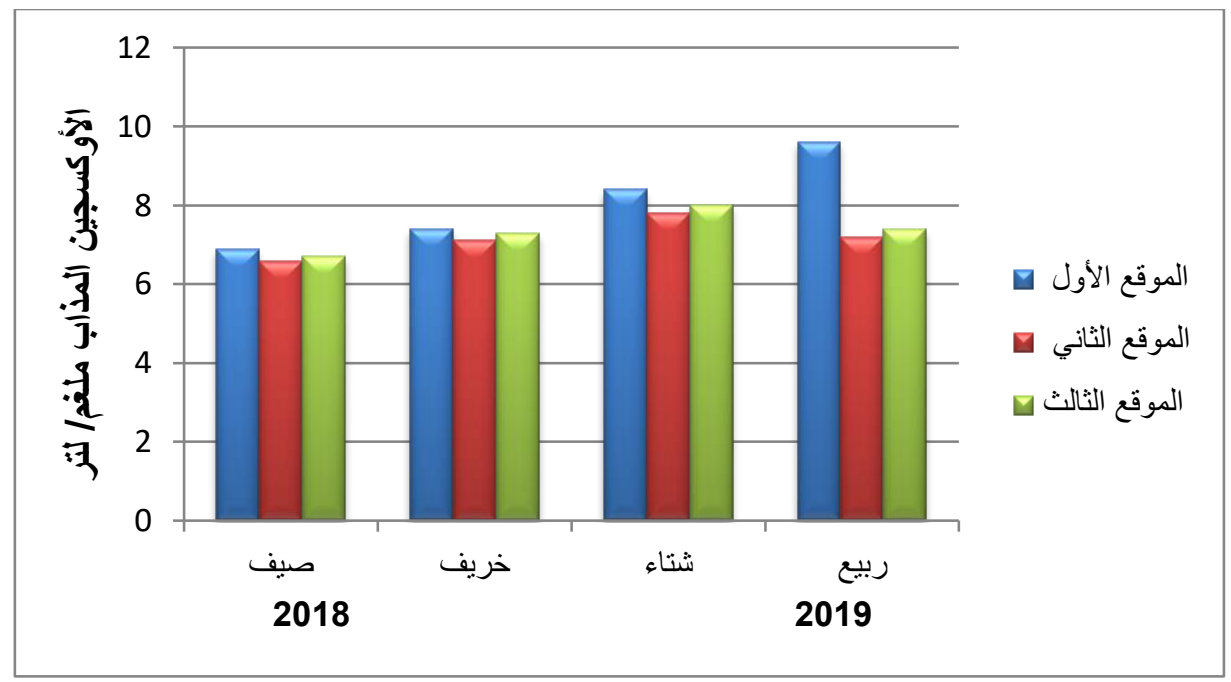

(الثكل6) قيم الأوكسجين المذاب للمواقع المدروسة خلال فصول السنة

المتطلب الحيوي للأوكسجين BOD5: لوحظت أعلى القيم 2.9 ملغم/لتر في الموقع الثاني في فصل الصيف (الثكل7) وربما يعود ذلك إلى عدد من الملوثات المدنية والزراعية والصناعية التي تدخل مجرى النهر عن طريق مياه الوديان المتصلة بجانبي نهر

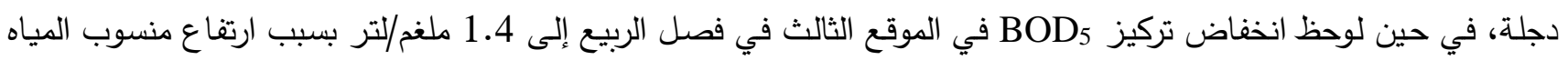

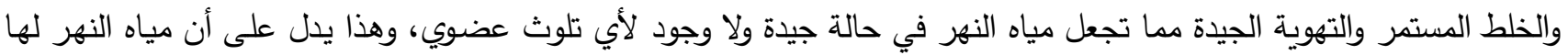

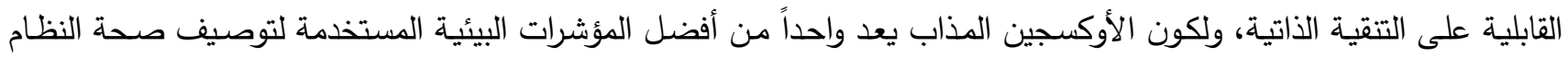
البيئي, وكذلك المتطلب الحيوي للأوكسجين BOD5 فإن قيمته تعني قابلية الجسم المائي على التنقية الذاتية [6]. يعد استهلاك

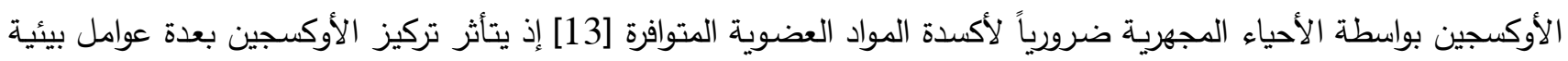

منها درجة الحرارة والتركيب الضوئي والتنفس والملوحة واضطرابات تيار الماء فضلاً عن فترة النهار [5].

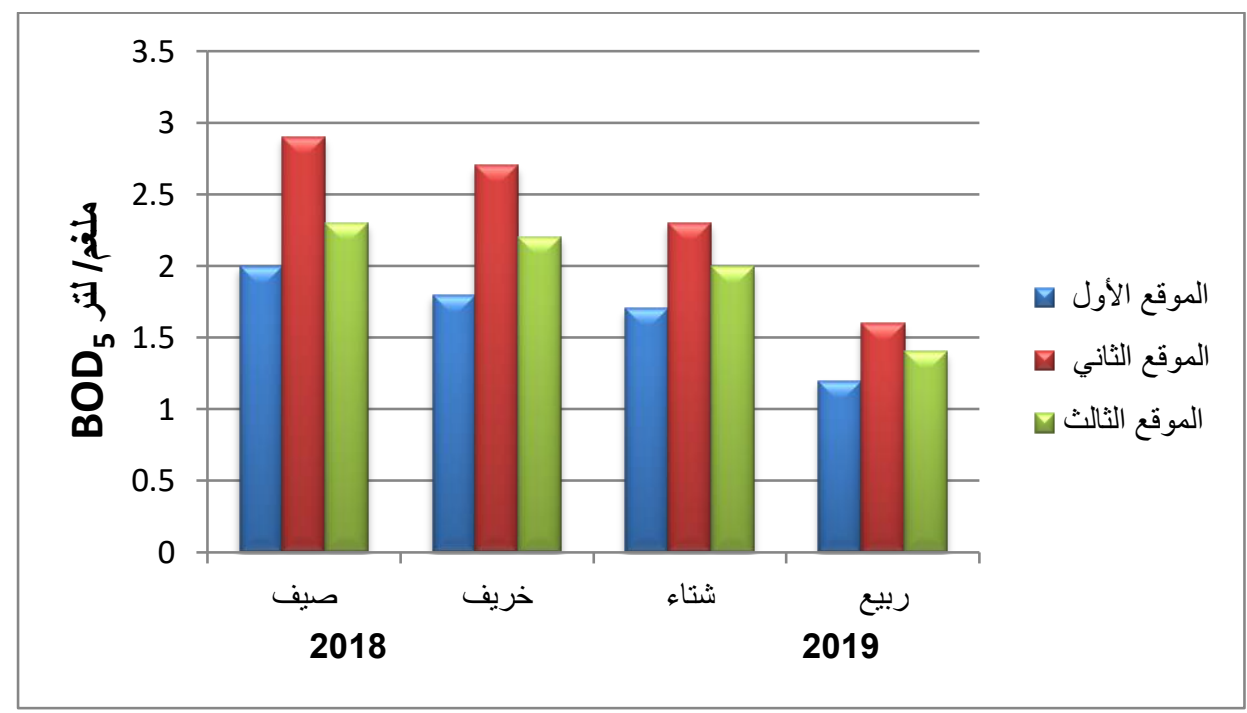

(الثكل7) قيم المتطلب الحيوي للأوكسجين للمواقع المدروسة خلال فصول السنة

العسرة الكلية: يوضح (الثكل8) أن قيم العسرة الكلية قد تراوحت ما بين 130 و 338 ملغم/ لتر، ويعد هذا التفاوت بين تراكيز العسرة الكلية طبيعياً اعتماداً على تركيز الأيونات الموجبة لاسيما الكالسيوم والمغنيسيوم وهي أكثر الأيونات المسببة للعسرة، فضلاً

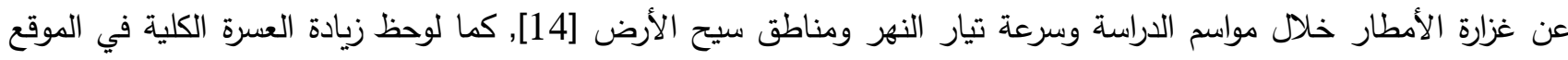


الثاني في فصل الثتاء إلى 338 ملغم/لتر، وهذا نتيجة وصول جزء من تربة الضفاف وانجراف الملوثات والتدفقات من الأراضي

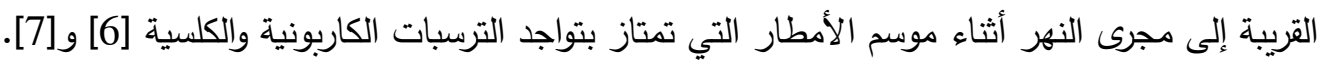

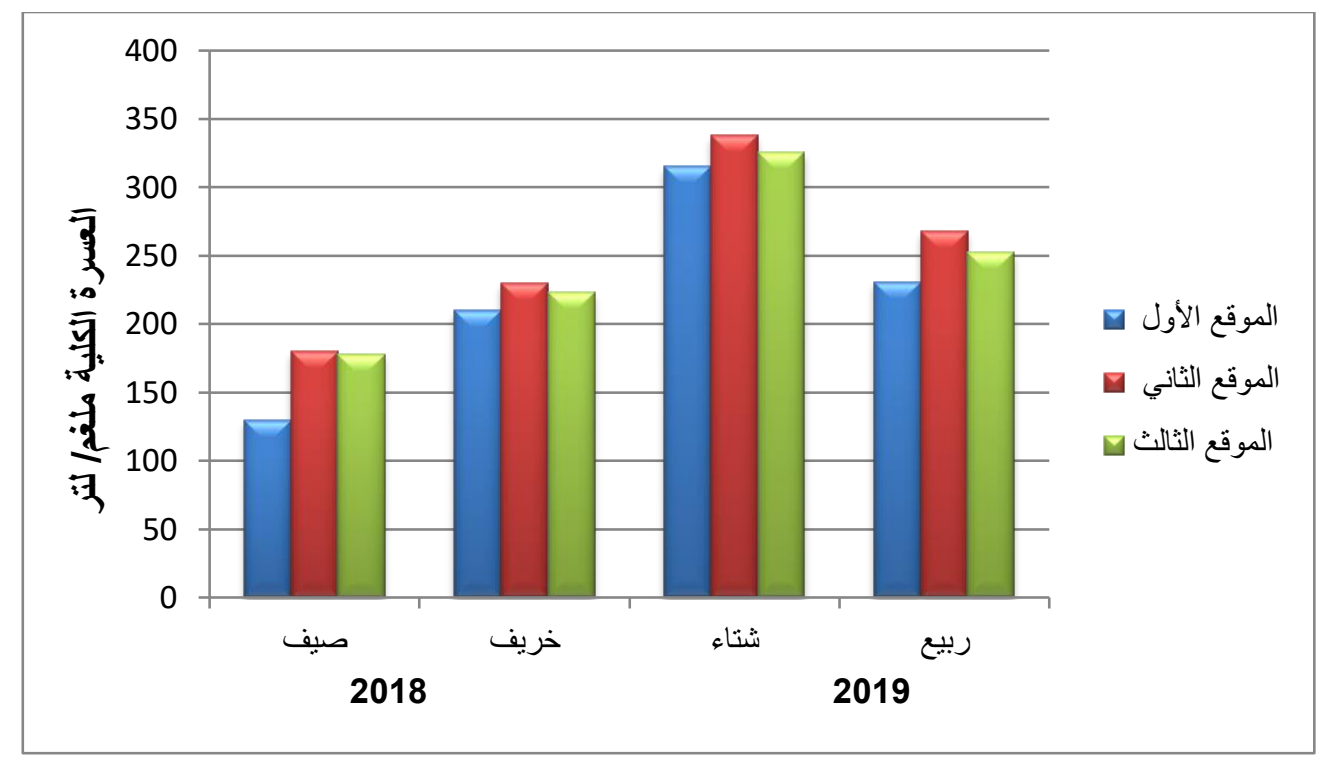

(الثكل8) قيم العسرة الكلية للمواقع المدروسة خلال فصول السنة

ايون الكلوريد Cl-1: أظهرت النتائج في (الثكل 9) ، وجود تباين في تركيز أيون الكلوريد إذ كانت القيم ما بين 18.9 ملغم/لتر في الموقع الأول في فصل الصيف و29.9 ملغم/لتر في الموقع الثاني في فصل الثتاء ويرجع السبب في هذا إلى وصول مياه

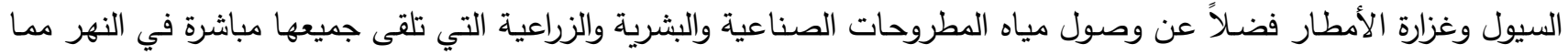
أدت إلى ارتفاع تركيز أيون الكلوريد، إلا أنها تعاود الانخفاض نتيجة للاختلاط المستمر وسرعة الاهرة الجريان وزيادة منسوب الماء [6]. يعد أيون الكلوريد من المعايير المهمة لتحديد نوعية المياه الخام، يتولد أيون الكلوريد من التكوينات الجيولوجية ولاسيما الصنئ الصنور الرسوبية بنتاج عملية التجوية وتكوينات التربة والمياه الجوفية والسطحية.

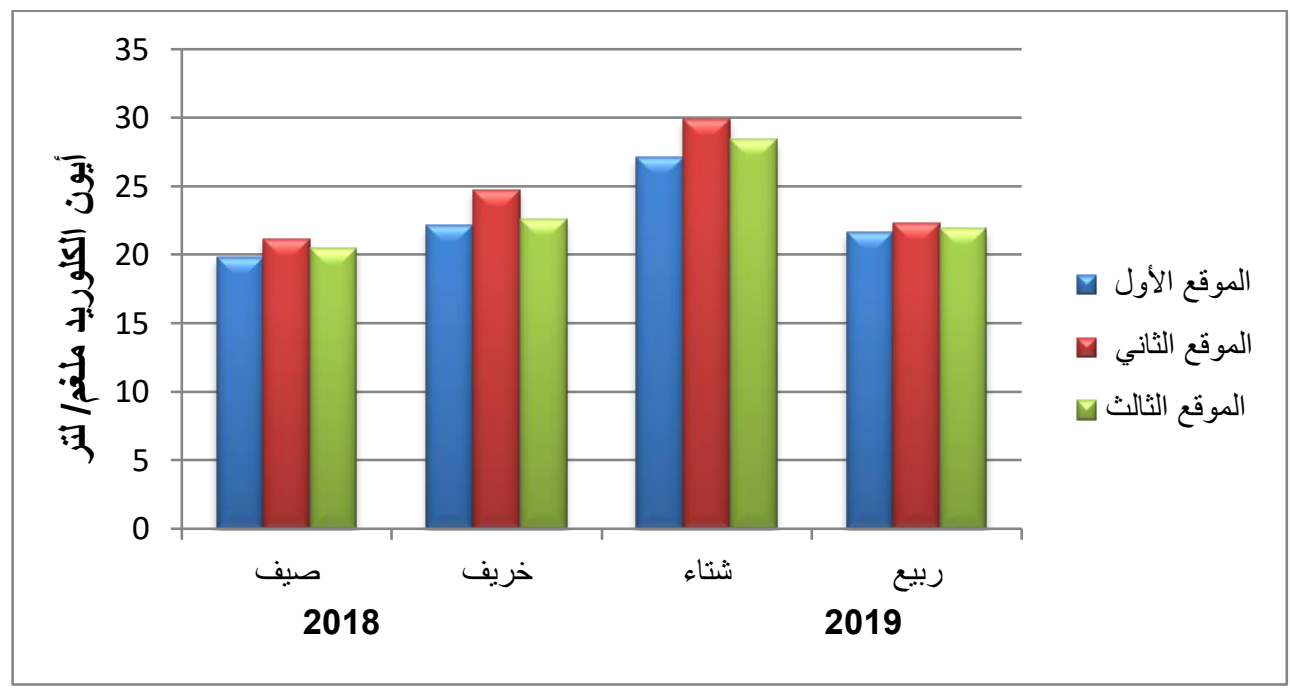

(الثكل9) قيم أيون الكلوريد للمواقع المدروسة خلال فصول السنة 
أيون الكبريتات 2-So4: تثير نتائج الكبريتات الى انخفاض تراكيز الأيون خلال فصلي الثتاء والربيع إلى 120 ملغم/لتر في الموقع الأول (الثكل 10)، وقد يكون ذلك بسبب عامل التخفيف والانتثار وزيادة منسوب مياه النهر ، في حين ارتفعت القيمة إلى 177

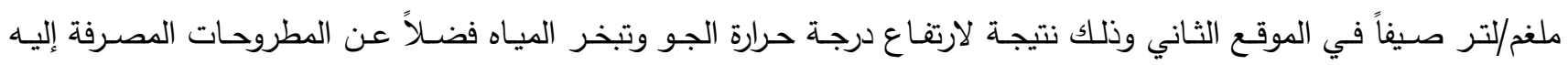

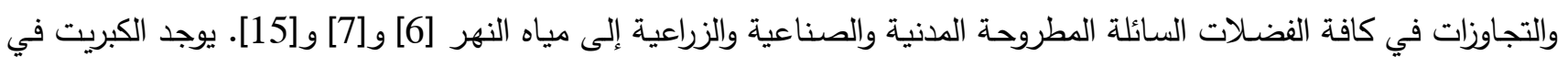
المياه السطحية وبصورة طبيعية على شكل أيون الكبريتات أو متحد مع أيونات موجبة تنشأ من العمليات الجيولوجية أو من أكسدة

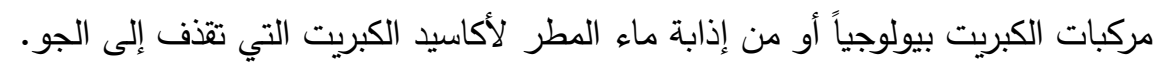

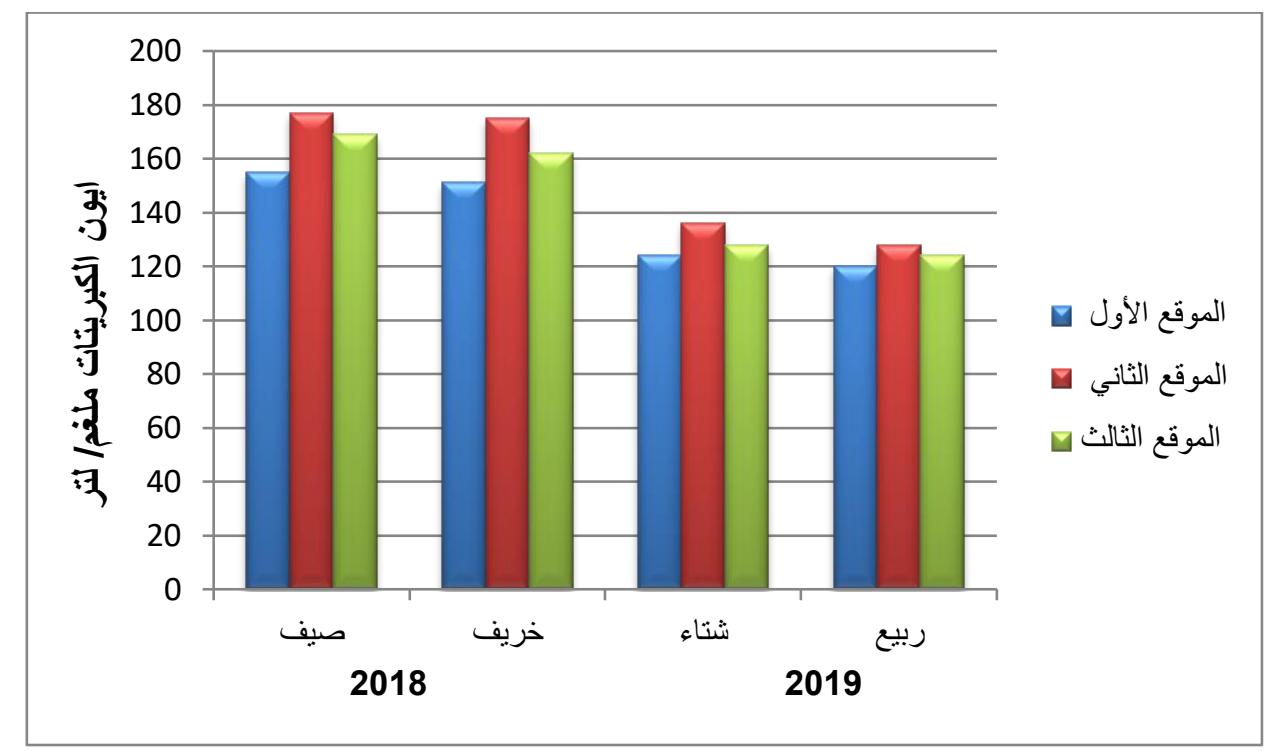

(الشكل10) قيم أيون الكبريتات للمواقع المدروسة خلال فصول السنة 
أيون النترات NO3:1: تثير النتائج المبينة في (الثكل 11) إلى أن تركيز أيون النترات في مياه نهر دجلة سجلت تبايناً في قيمها إذ تراوحت 0.09-0.176 ملغم/لتر، إذ ظهر أعلى تركيز في الموقعين الثاني و الثالث صيفاً بسبب انخفاض منسوب المياه وتئرت فتركيز

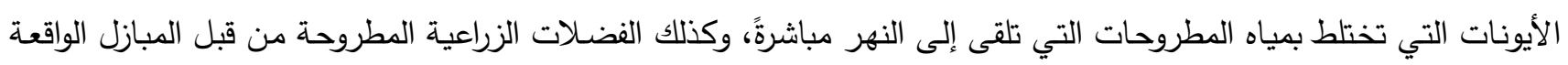

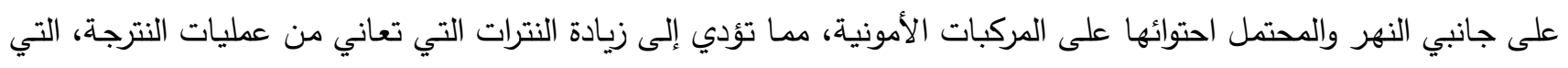
تتطلب حرارة مرتفعة [16]، إضافة إلى تبخر المياه، في حين انخفض تركيز أيون النترات الى 0.09 ملغم/لتر في الموقع الأول في

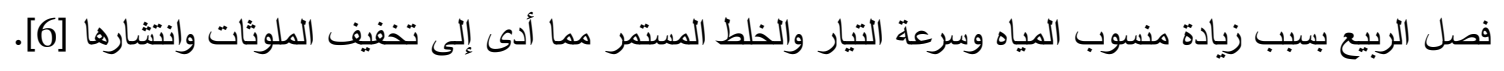

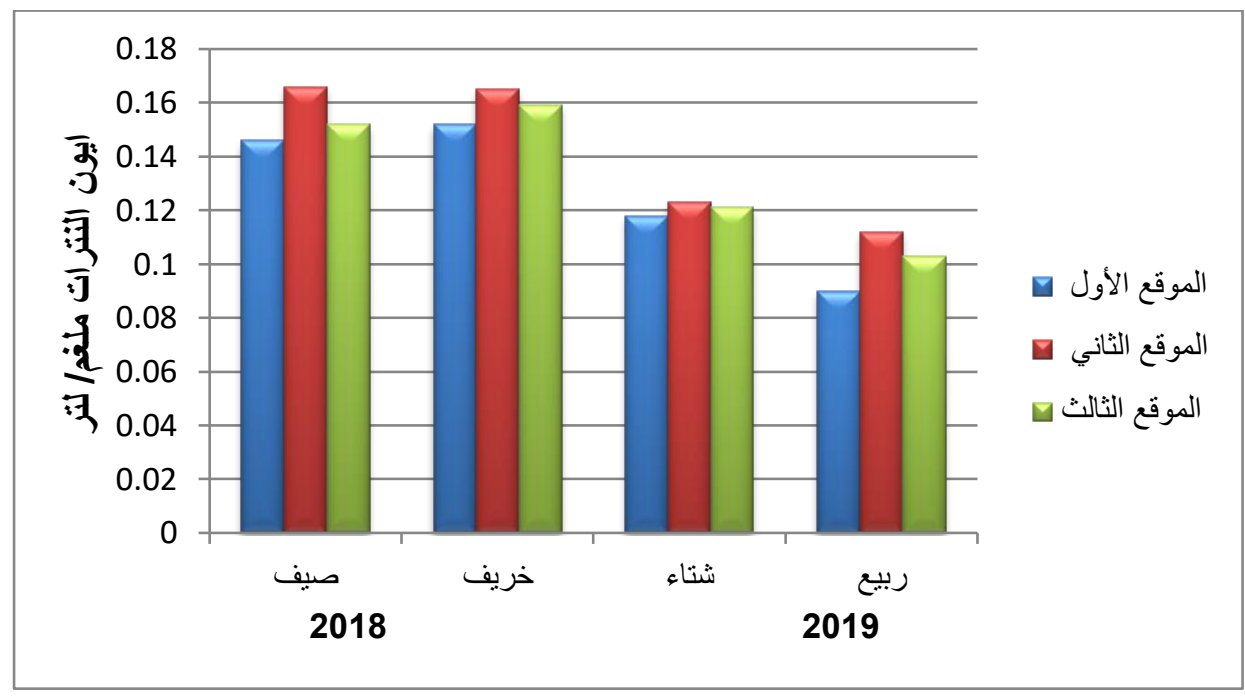

(الشكل11) قيم أيون النترات للمواقع المدروسة خلال فصول السنة

أيون الاورثوفوسفات PO ${ }^{-3}$ يلاحظ من (الثكل 12) و(الجدول 1) الارتفاع النسبي في تركيز أيونات الاورثوفوسفات 0.036 في 0. ملغم/لتر في فصل الثتاء في الموقع الثاني، ويعزى هذا إلى الارتفاع في استخدام مساحيق الغسيل والمنظفات الغنية لمركبات

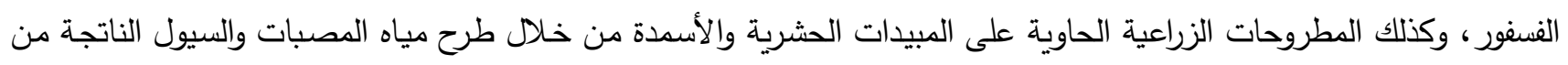

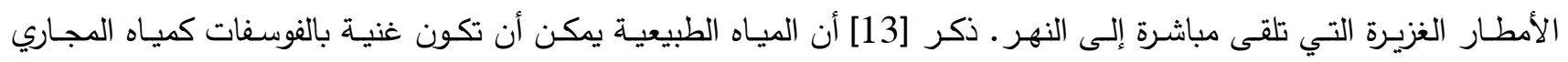

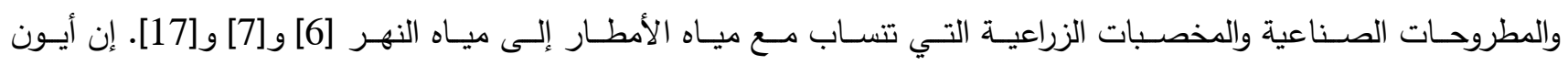
الاورثوفوسفات هو المركب السائد للفسفور غير العضوي في المياه الطبيعية الذي يستغل من قبل النباتات المائية والهائمات النباتية 


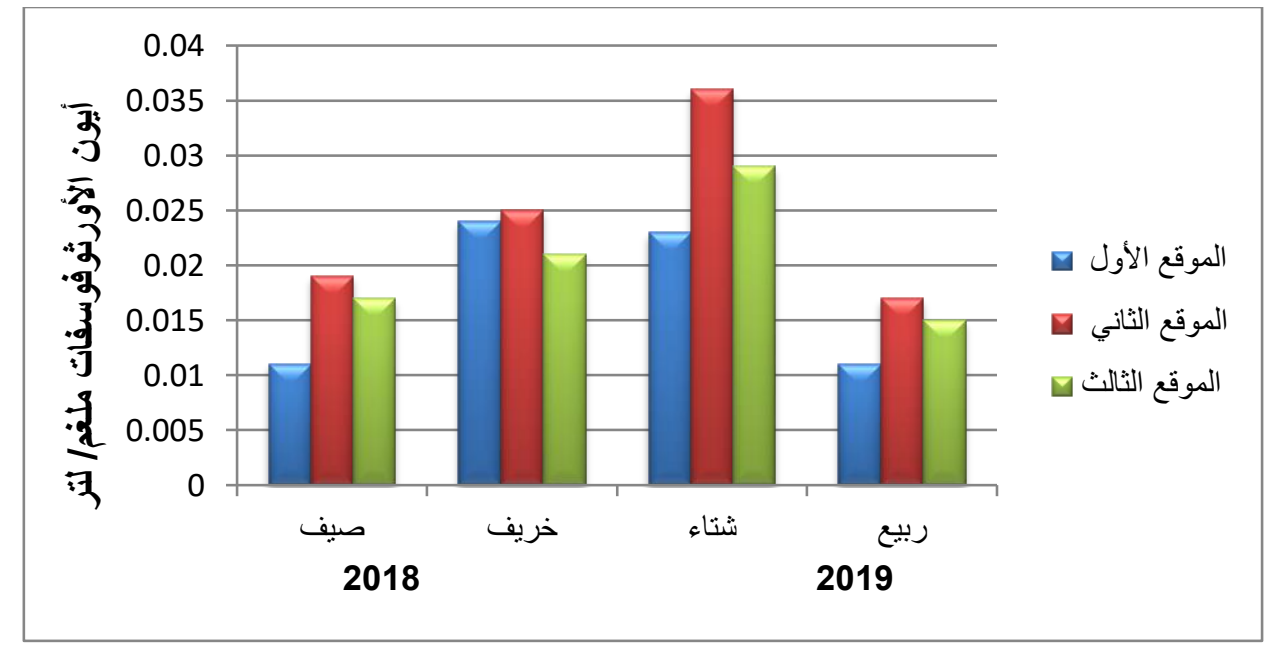

(الثكل12) قيم أيون الأورثوفوسفات للمواقع المدروسة خلال فصول السنة

Conclusions الاستنتاجات

توصلت الدراسة إلى الاستتاجات الآتية:

1- تقع أغلب قيم الخصائص الفيزيائية والكيميائية ضمن الحدود الطبيعية وتتطابق مع المواصفات القياسية العراقية وطبقاً لنظام صيانة الانهار العراقية لعام 1967.

2- تعد مياه نهر دجلة مياه جيدة وصالحة للاستخدام البشري والاستخدامات الأخرى، كما أنها المصدر الوحيد للمياه الخام لمحطات الإسالة.

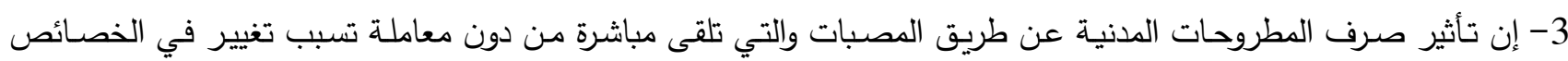

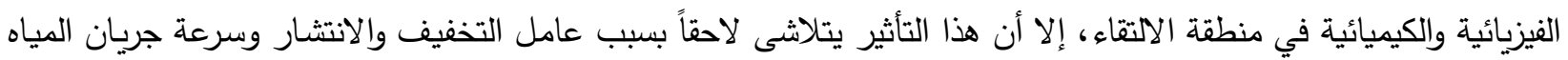
وزيادة منسوب الماء، فضلاً عن قدرة النهر على التتقية الذاتية.

Recommendations التوصيات 1- إجراء دراسات دورية شهرية أو فصلية على مياه نهر دجلة ضمن مدينة الموصل، وذلك لأنها معرضـة للاختلاط المستمر مع نئ مياه المصبات التي تطرح بدون معالجة. 2- دراسة تركيز المعادن الثقيلة مثل الرصاص، والكادميوم، والخارصين في مياه نهر دجلة ضدن مدينة الموصل.

\section{References المصادر}

[1] Chang, K.H.; A. Amano; W.M. Todd.; T. Isobe; R. Maneja, F.P. Siringan, H. Imai and S. Nakano, Environmental Research in Asia. pp: 261-267, (2009).

[2] Flayyh, H. A. And Rasheed, Kh. A., Ass. Univ. Bull. Environ. Res. 19 (1), March (2016), (In Arabic).

[3] APHA, Standard Methods for the Examination of Water and Wastewater, USA, pp: 594-610, (1998). 
[4] Winer, E.R., Application of environmental chemistry. Boca Raton, London, U.K., (2000).

[5] Green, B.W.; R. David and E. Clond, Water exchange to rectify low dissolved Oxygen. Annual Technical Report. pp: 101-104, (2000).

[6] Al- Sarraj, Eman Sami Yaseen, Ph. D. Thesis Biology, Zoology, College of Science University of Mosul, (2013), (In Arabic).

[7] Ankcorn, P.D. Clarifying Turbidity-The potential and Limitations of Turbidity as a Surrogate for Water Quality Monitoring, Proceedings of the Georgia Water Resources Conf, American public Health Association, pp: 2-11, (2003).

[8] Al- Mashhadani, M.H.S., Abdul-Aziz Y. T., Saffawi, Omar, M.R. International and Scientific Conference Followed by the College of Science University of Tikrit, pp: 38-40, (2018), (In Arabic).

[9] Potapova, M. and Charles, D., Freshwater Biology, 48: 1311- 1328, (2003).

[10] Nashaat, M. R., Ph. D. Thesis; University f Baghdad, Iraq. pp: 183, (2010).

[11] Al- Obaidi, G. S. A., University of Baghdad- Iraq, pp: 102, (2006).

[12] Smith, R., "Current Methods in Aquatic Science", University of Waterloo, Canada, (2004).

[13] Goel, P.K. Water Pollution. Causes, Effects and Control. 2nd Ed, Reprint New Age international (P) Limited, New Delhi. pp: 124, (2008).

[14] Namrawe, Adel, PhD thesis, College of Science University of Baghdad, (2005), (In Arabic).

[15] Hassan, F. M., Iraq. J. Um - salama for science, 1 (1), pp: 119 - 124, (2004).

[16] Gachter, R.; Steingruber, S.M.; Reinharadt, M. and Wehrli, B. Aquat. Sci., 66: 117- 122, (2004).

[17] Al Assaf, Azhar Y.R., Abdalaziz, Y.T., Al-Saffawi, J. Edu. and Sci., 27 (1): 81-83, (In Arabic). 
Journal of Education and Science (ISSN 1812-125X), Vol: 29, No: 3, 2020 (32-45)

[18] Puri, P.J., Yenkie, M.K.N., Rana, D.B. and Meshram, S.U. European J. Exper. Biol. Vol. 5, No. 2, pp: 37-52, (2015). 
جدول (1): معدل تراكيز الخصائص الفيزيائية والكيميائية للمواقع المدروسة خلال فصول السنة 2018- 2019

\begin{tabular}{|c|c|c|c|c|c|c|c|c|c|c|c|c|}
\hline \multicolumn{3}{|c|}{ فصل الربيع 2019} & \multicolumn{3}{|c|}{ فصل الثتاء 2019 -2018 } & \multicolumn{3}{|c|}{ فصل الخريف 2018} & \multicolumn{3}{|c|}{ فصل الصيف 2018} & \multirow[t]{2}{*}{ المواقع } \\
\hline موقع 3 & موقع 2 & موقع 1 & موقع 3 & موقع 2 & موقع 1 & موقع 3 & موقع 2 & موقع 1 & موقع 3 & موقع 2 & موقع 1 & \\
\hline 18.1 & 18.0 & 17.4 & 14.9 & 14.7 & 14.2 & 23.3 & 23.4 & 23.0 & 25.4 & 25.1 & 25.0 & درجة الحرارة م \\
\hline 22.2 & 23.1 & 20.9 & 16.2 & 16.7 & 12.3 & 3.14 & 3.21 & 3.1 & 3.24 & 3.27 & 2.8 & العكورة NTU \\
\hline 334 & 335 & 332 & 318 & 321 & 319 & 287 & 293 & 272 & 270 & 287 & 266 & التوصيل الكهربائي \\
\hline 8.0 & 7.6 & 7.9 & 8.2 & 7.7 & 8.1 & 7.71 & 8.01 & 8.07 & 7.87 & 8.02 & 8.50 & الدالة الحامضية (pH) \\
\hline 7.4 & 7.2 & 9.6 & 8.0 & 8.7 & 8.4 & 7.3 & 7.1 & 7.4 & 6.7 & 6.6 & 6.9 & الأوكسجين المذاب ملغم/لتر \\
\hline 1.4 & 1.6 & 1.2 & 2.0 & 2.3 & 1.7 & 2.2 & 2.7 & 1.8 & 2.3 & 2.9 & 2.0 & BOD5 ملغ/لتر \\
\hline 252 & 268 & 231 & 326 & 338 & 315 & 223 & 230 & 210 & 178 & 180 & 130 & العسرة الكلية ملغم/تتر \\
\hline 21.9 & 22.3 & 21.6 & 28.4 & 29.9 & 27.1 & 22.6 & 24.7 & 22.2 & 20.5 & 21.1 & 19.8 & أيون الكلوريد ملغم/لتر \\
\hline 124 & 128 & 120 & 128 & 136 & 124 & 162 & 175 & 151 & 169 & 177 & 155 & أيون الكبريتات ملغم/لتر \\
\hline 0.103 & 0.112 & 0.09 & 0.121 & 0.123 & 0.118 & 0.159 & 0.165 & 0.152 & 0.152 & 0.176 & 0.146 & أيون النترات ملغم/تتر \\
\hline 0.015 & 0.017 & 0.011 & 0.029 & 0.036 & 0.023 & 0.021 & 0.025 & 0.024 & 0.017 & 0.019 & 0.011 & أيون الأورثوفوسفات ملغم/تزر \\
\hline
\end{tabular}

